\title{
太湖流域 零点”行动的环境效果分析
}

\section{黄文铨 杨桂山 许朋柱}

(中国科学院南京地理与湖泊研究所, 南京 210008)

提 要 太湖流域点源污染治理的 零点”行动对减轻太湖及流域水质的污染具有积极的 作用. 削减 COD 量占入湖 COD 总量的 19.1\%, 1998 年主要入湖河道 COD 监测浓度年平均值比 1997 年平均值下降 $26.7 \%, 1998$ 年太湖湖水 COD 年平均浓度比 1997 年的平均浓度下降了 21. $2 \%$, 这在一定的程度上遏制了太湖水质恶化的趋势. 但若从根本上改善太湖水质, 尚需结合流域 地区内其它污染治理措施, 形成综合治理.

关键词 “零点”行动 水环境 效果 太湖

分类号 $\mathrm{P} 343.3$

湖泊及其流域水资源是人类赖以生存的重要资源.由于人口增加、经济发展迅速 , 水污染 治理滞后 ,大量污水未经处理就直接排放入河、湖水体 湖泊及其流域的生态系统受到严重破 坏, 造成水质污染, 富营养化日趋严重，导致流域的水质性水资源危机，直接影响到流域内社会 经济的可持续发展，因而引起社会各界的广泛关注和研究 ${ }^{[1-4]}$.

自 60 年代以来，太湖水质的污染明显加剧，表现为平均每 10 年左右水质下降一个级别. 目前全流域 $70 \%$ 的河湖受到污染，80\%的河流水质达不到国家规定的地面 III 类水标准，全湖 水质达富营养、局部重富营养水平，严重地影响到湖区工农业生产的发展和人民生活饮用水的 安全. 太湖的水环境问题已经引起了各级政府、党和国家领导人的高度重视. 有关太湖及其流 域水环境问题的研究得到了有效的重视 ${ }^{[5-8]}$. 为有效地控制太湖富营养化污染的进程, 减轻 太湖水质污染的危害，国务院于 1997 年批准了“太湖水污染防治 九五”计划和 2010 年规划” (以下简称 规划”)的治理方案, 并于 1998 年底联合流域内二省一市实行了太湖流域污染源达 标排放行动 (简称 零点” 行动) “零点” 行动在一定程度上削减了外源营养盐负荷，对遏制水环 境恶化起到了一定作用 ${ }^{[9-11]}$. 但是，从 1999 年和 2000 年太湖水质监测资料来分析，太湖的水 环境问题远没有解决. 为客观地评价 零点”行动的水环境效果，从行动前 (以 1997 年为基准) 后(以 1998 年为基准)的入湖河道水质、入湖污染物削减率和湖体水质变化等方面进行了分析 和评价.

\section{1 零点” 行动概述}

根据 规划”的要求，太湖流域地区内日排工业废水 $100 \mathrm{t}$ 和 $\mathrm{COD}_{\mathrm{Cr}} 30 \mathrm{~kg}$ 以上的重点排污企 业 1035 家，在 1998 年底以前达标排放 (即所排工业废水中 $\mathrm{COD}_{\mathrm{Cr}}$ 浓度小于 $100 \mathrm{mg} / \mathrm{L}$ ) ,至 
1999 年元月 1 日止, 通过工程验收达标排放的企业有 863 家, 正在调试或停产治理的有 29 家，责令关闭的有 24 家，其它原因破产或停产的 101 家，总达标率为 $97.3 \%$.其中，江苏在列 入 零点” 行动的 770 家重点排污单位的治理中，通过工程验收达标排放的 651 家，正在调试的 7 家，责令关闭的 9 家，由于其它原因破产或停产的 101 家，未完成治理任务停产的 2 家，总完 成率 $99.7 \%$.

达标排放以来 江苏 770 家重点点源污染物排放量处于下降趋势 (表 1) “, 零点” 行动后的 1998 年 12 月 $\mathrm{COD}$ 排放量比行动前的 1997 年平均月排放量减少 $73.8 \%$;至 1999 年 9 月以 后，COD排放量趋于稳定，为 $2028 \mathrm{~V}$ 月一 $2237 \mathrm{~V}$ 月，比 1997 年平均月排放量削减了 $84.0 \%$ 一 $82.4 \%$ 较达标前有较大幅度的削减.

表 1 零点”行动前后江苏 770 家重点点源 $\mathrm{COD}_{\mathrm{cr}}$ 排放量变化状况 $(V$ 月 $)$

Tab.1 Variations of $\mathrm{COD}_{\mathrm{Cr}}$ in 770 main waste sources before

and after the" zero" actions in Jingsu

\begin{tabular}{ccccccccc}
\hline \multirow{2}{*}{ 时间 } & $\begin{array}{c}1997 \text { 年 } \\
\text { 平均 }\end{array}$ & $\begin{array}{c}1998 \text { 年 } \\
1 \text { 月 }\end{array}$ & $\begin{array}{c}1998 \text { 年 } \\
12 \text { 月 }\end{array}$ & $\begin{array}{c}1999 \text { 年 } \\
5 \text { 月 }\end{array}$ & $\begin{array}{c}1999 \text { 年 } \\
\text { 月 }\end{array}$ & $\begin{array}{c}1999 \text { 年 } \\
11 \text { 月 }\end{array}$ & $\begin{array}{c}2000 \text { 年 } \\
5 \text { 月 }\end{array}$ & $\begin{array}{c}2000 \text { 年 } \\
\text { 月 }\end{array}$ \\
\hline 排放量 & 12695 & 9191 & 3327 & 2714 & 2028 & 2129 & 2237 & 2114 \\
\hline
\end{tabular}

\section{2 “零点” 行动环境效果分析}

本次 零点” 行动的考核指标为 COD ,因此, 本文在分应 零点” 行动环境效果时, 仅采用 COD 指标.

\section{1 对入湖河道水质变化的影响}

太湖流域内重点排污企业位于城填地区，其污染物排放后大都经河道入湖. 根据 规划”， 入湖污染物主要经入湖河道入湖 其中河道带入 COD 量占入湖总量的 $81.6 \%$. 因此, 分析 零 点”行动前后入湖河道水质的变化, 可以反映出 零点”行动的水环境效果.

根据 1997 年和 1998 年太湖主要入湖河道 COD 浓度监测资料,利用 1998 年 7 月、9 月、 11 月、12 月及 1998 年平均值与 1997 年平均值的比较 结果如表 2 所示. 表 2 中, 1998 年 7 月 各河道 COD 监测浓度与 1997 年平均值比较, 各河道均有一定程度的下降, 平均下降了 $14.8 \%$ 其中乌溪港桥河下降幅度最大 ,下降率为 $20.3 \%$,殷村港、大溪港桥和节制闸下降幅 度最小,下降率均为 $10.5 \% .1998$ 年 9 月各河道 COD 监测浓度与 1997 年平均值比较, 平均下 降了 $39.8 \%$ ，其中，除合溪河和大港桥河有所反弹，分别上升了 $17.5 \%$ 和 $6.1 \%$ 外，其余河道 均有一定程度的下降，浓度下降的河道中，大溪港桥河下降幅度最大，下降率为 $68.4 \%$,新塘 河下降幅度最小,下降率为 $16.2 \% .1998$ 年 11 月各河道 COD 监测浓度与 1997 年平均值比 较，平均下降了 $31.9 \%$, 除合溪河有所反弹，上升 $12.3 \%$, 其余河道均有一定程度的下降，浓度 下降的河道中，大钱口河和社渎港河下降幅度最大，分别下降了 $55.4 \%$ 和 $50.6 \%$, 夹浦河和小 溪港桥河下降幅度最小, 分别下降了 $8.8 \%$ 和 $12.3 \% .1998$ 年 12 月各河道 COD 监测浓度与 1997 年平均值比较, 平均下降了 $20.5 \%$,除大溪港桥河、庙港桥河和小溪港桥河有所反弹 ,分 别上升 $60.5 \%$ 、 $16.7 \%$ 和 $6.8 \%$ 外，其余河道均有一定程度的下降，浓度下降的河道中，大港桥 
河和姚巷桥河下降幅度最大，分别下降了 $57.6 \%$ 和 $44.7 \%$,大钱口河和新港口河下降幅度最 小，仅为 $3.6 \%$ 和 $7.3 \%$.总体而言，1998 年各河道 COD 监测浓度年平均值与 1997 年平均值 比较，各河道均有一定程度的下降，平均下降了 $26.7 \%$, 其中吴塘桥河和社渎港河下降幅度最 大 分别下降了 $39.6 \%$ 和 $38.4 \%$,合溪河和大溪港桥河下降幅度最小, 分别下降了 $1.8 \%$ 和 $10.1 \%$, 说明 零点”行动对削减入湖河道中 COD 浓度是有效的.

表 2 太湖主要入湖河口 $\mathrm{COD}_{\mathrm{Mn}}$ 浓度 零点”行动前后变化的比较 $(\mathrm{mg} / \mathrm{L})$

Tab. 2 Comparisons of water pollutant concentrations in input rivers before and after the" zero" actions in Taihu Lake in 1998

\begin{tabular}{|c|c|c|c|c|c|}
\hline 河道断面 & $\begin{array}{c}1998 \text { 年 } 7 \text { 月比 } \\
1997 \text { 年平均值 } \\
\text { 下降 }(\%)\end{array}$ & $\begin{array}{c}1998 \text { 年 } 9 \text { 月比 } \\
1997 \text { 年平均值 } \\
\text { 下降 }(\%)\end{array}$ & $\begin{array}{c}1998 \text { 年 } 11 \text { 月比 } \\
1997 \text { 年平均值 } \\
\text { 下降 }(\%)\end{array}$ & $\begin{array}{c}1998 \text { 年 } 12 \text { 月比 } \\
1997 \text { 年平均值 } \\
\text { 下降 }(\%)\end{array}$ & $\begin{array}{c}1998 \text { 年平均值比 } \\
1997 \text { 年平均值 } \\
\text { 下降 }(\%)\end{array}$ \\
\hline 姚巷桥 & -17.9 & -67.5 & -16.3 & -44.7 & -36.6 \\
\hline 百渎港 & -14.9 & -52.7 & -37.8 & -17.6 & -30.7 \\
\hline 黄埝桥 & -17.5 & -60.8 & -13.4 & -17.5 & -27.3 \\
\hline 殷村港 & -10.5 & -18.4 & -36.8 & -23.7 & -22.4 \\
\hline 社渎港 & -12.4 & -50.6 & -50.6 & -40.4 & -38.4 \\
\hline 大浦口 & -17.3 & -33.3 & -44.0 & -32.0 & -28.9 \\
\hline 官渎桥 & -16.4 & -31.5 & -42.5 & -19.2 & -27.4 \\
\hline 乌溪港桥 & -20.3 & -23.7 & -45.8 & -32.2 & -30.5 \\
\hline 大港桥 & -12.1 & 6.1 & -48.5 & -57.6 & -27.9 \\
\hline 夹浦 & I & -17.6 & -8.8 & -21.9 & -16.2 \\
\hline 合溪 & -17.5 & 17.5 & 12.3 & -19.3 & -1.8 \\
\hline 新塘 & -17.6 & -16.2 & -23.0 & -32.7 & -22.3 \\
\hline 新港口 & -15.7 & -25.5 & -49.0 & -7.3 & -24.3 \\
\hline 小梅口 & -15.4 & -26.9 & -44.2 & -29.4 & -29.0 \\
\hline 大钱口 & -19.6 & -26.8 & -55.4 & -3.6 & -26.3 \\
\hline 大溪港桥 & -10.5 & -68.4 & -22.4 & 60.5 & -10.1 \\
\hline 庙港桥 & -16.7 & -66.7 & -15.3 & 16.7 & -20.4 \\
\hline 小溪港桥 & -15.1 & -67.1 & -12.3 & 6.8 & -21.9 \\
\hline 雅浦桥 & -11.7 & -35.0 & -36.9 & -30.1 & -28.3 \\
\hline 吴塘桥 & -17.6 & -56.5 & -44.7 & / & -39.6 \\
\hline 节制闸 & -10.5 & -34.2 & -48.2 & -39.5 & -33.1 \\
\hline 平均 & -14.8 & -39.8 & -31.9 & -20.5 & -26.7 \\
\hline
\end{tabular}

2.2 对入湖污染物削减率的影响

据国家环保局南京环科所 太湖流域污染源调查及污染负荷分析” (1997 年) 流域内重点 工业污染源排放 COD 量占入湖总量的 $25.87 \%$. 本次 零点” 行动中，重点工业污染源排放 
COD 量的削减率以江苏为例 (表 1 ), 1998 年 12 月的排放量与 1997 年平均月排放量比较, 削 减率为 $73.8 \%$. 因此“, 零点”行动对削减污染物入湖总量的比例中，COD 为 $19.1 \%$.

\section{3 对湖体水质的影响}

据中国科学院南京地理与湖泊研究所太湖生态系统研究站逐月监测资料的统计，结果见 表 3 所示.

以 1997 年为 零点”行动前基准年, 1998 年为 零点” 行动效果年进行比较,湖水 COD 浓 度下降了 $21.2 \%$. 说明经过 1998 年 零点” 行动, 湖水水质有所改善. 但 1999 年和 2000 年度 水质再度恶化，其中，1999 年均值比 1998 年均值上升 $2.3 \%$,COD 浓度上升的湖区有贡湖、宜 兴武进片区、湖心区和东太湖区，上升幅度在 $2.5 \%$ 至 $6.3 \%$ 之间，说明这一地区的污染治理有 所松懈，COD 浓度下降的湖区有五里湖、梅梁湾和湖州长兴片区，下降幅度在 $1.7 \%$ 至 $6.7 \%$ 之间，说明这一地区的污染治理得到重视. 2000 年均值比 1997 年均值上升 5.9\% ,COD 浓度 上升的湖区有五里湖、贡湖、湖心区和东太湖区，上升幅度在 $1.5 \%$ 至 $24.5 \%$ 之间;COD 浓度 下降的湖区有梅梁湾、宜兴武进片区和湖州长兴片区，下降幅度在 $4.4 \%$ 至 $15.7 \%$ 之间.

表 31997 年至 2000 年度太湖水质 $\mathrm{COD}_{\mathrm{Mn}}$ 变化状况 $(\mathrm{mg} / \mathrm{L})$

Tab. 3 Variations of water quality from the year of 1997 to 2000 in Taihu Lake

\begin{tabular}{|c|c|c|c|c|}
\hline 湖区 & 1997 年 & 1998 年 & 1999 年 & 2000 年 \\
\hline 五里湖 & 7.74 & 6.94 & 6.82 & 8.14 \\
\hline 梅梁湾 & 5.97 & 5.69 & 5.31 & 5.44 \\
\hline 贡湖 & / & 3.75 & 3.88 & 4.67 \\
\hline 宜兴武进片区 & l & 6.35 & 6.51 & 5.85 \\
\hline 湖州长兴片区 & / & 4.51 & 4.33 & 3.80 \\
\hline 湖心区 & 4.56 & 3.86 & 4.01 & 4.46 \\
\hline 东太湖 & / & 3.31 & 3.52 & 3.36 \\
\hline 全太湖平均 & 6.09 & 4.80 & 4.91 & 5.10 \\
\hline
\end{tabular}

\section{3 小结及讨论}

(1) 零点” 行动对减轻太湖水质污染具有积极的作用, 其中 COD 减轻幅度在 $19.1 \%-$ $26.7 \%$.

(2) 太湖流域水污染治理达标行动经过一年的努力,1998 年底基本完成，再经过 1999 年 上半年的深入和巩固，至 1999 年 9 月，达标行动的重点污染源污染物排放量稳定在一定的水 平上. 如以江苏为例，参与 零点” 行动的 770 家重点点源 1997 年 $\mathrm{COD}_{\mathrm{Cr}}$ 平均的排放量为 $12695 \mathrm{~V} /$ 月 ,1998 年 1 月的排放量为 $9191 \mathrm{~V}$ 月, 1998 年 12 月减少至 3327V/月，至 1999 年 9 月 后, $\mathrm{COD}_{\mathrm{Cr}}$ 排放量稳定在 $2028-2237 \mathrm{~V}$ 月之间.

(3) 太湖湖体 $\mathrm{COD}_{\mathrm{Cr}}$ 浓度 经过 1998 年的 零点”行动，水质有所改善，但 1999 年和 2000 年度水质再度恶化, 但未超过 1997 年的水平, 说明 零点” 行动对太湖水环境的改善具有积极 的作用. 但由于其它污染源未得到同步有效的控制, 单项的工业点源污染( 零点行动”)的治理 效果, 整体而言, 其作用是有限的, 仅能在一定的时间段内遏制了太湖水质恶化的趋势. 若从根 本上改善太湖水质, 尚需结合流域地区内其它污染治理措施, 形成综合治理. 


\title{
参 考 文 献
}

1 黄文钰, 吴延根, 舒金华. 中国主要湖泊水库的水环境问题与防治建议. 湖泊科学, 1998, 10(3) 83-90

2 舒金华,黄文钰, 吴延根.中国湖泊营养类型的分类研究. 湖泊科学 ,1996 8(3):193-200

3 秦伯强. 太湖水环境面临的主要问题、研究动态与初步进展. 湖泊科学, 1998, 10(4) :1-9

4 万 - ,贾 利.淮河流域 97 达标”一年来的回顾. 水资源保护, 1999, 2:42-63

5 刘鸿志,任隆江, 胡 明.太湖水污染防治对策. 环境保护科学, 1998,24(6) 5-12

6 诸 敏.太湖水质变化趋势及其保护对策.湖泊科学 ,1996 8(2):133-138

7 蔡启铭, 高锡芸, 陈宇伟等. 太湖水质的动态变化及影响因子的多元分析. 湖泊科学, 1995,7(2):97-106

8 杨清心 李文潮, 俞 林等. 东太湖围栏养殖及其环境效应. 湖泊科学, 1995,7(3) 256-262

9 陈荷生.太湖流域城市水环境综合治理.城市环境, 2000 5 34-38

10 李荣刚, 夏源陵, 吴安之等.江苏太湖地区水污染物及其向水体排放量.湖泊科学, 2000,12(2): 147-153

11 奚永淑，宋再荣，石晓鹏. 江苏省工业污染源排放情况调查. 能源研究与利用, 2000,13-6

\section{Environmental Effects of " Zero" Actions in Taihu Basin}

\author{
HUANG Wenyu YANG Guishan XU Pengzhu \\ ( Nanjing Institute of Geography and Limnology, Chinese Academy of Sciences, Nanjing 210008 , P. R. China)
}

\begin{abstract}
Since the 1960s , the water pollution is pricked up in Taihu Lake. The water quality is decreased about one degree per 10 years , $70 \%$ of the rivers and lakes are polluted, and $80 \%$ of river water quality can not fit the need of national quality standard of Class III of surface water. At present , the whole lake' water is eutrophication, and part of the lake is heavy eutrophication.

The" Zero" actions have good effect on lightening the water pollution in Taihu Lake, and keep within limits the water quality decreasing in some degree. The COD concentration of input rivers was decreased $26.7 \%$ averagely from the year of 1997 to 1998 . Among the input rivers, the river of $\mathrm{COD}$ concentration maximum decrease was at Wutangqiao, $-39.6 \%$; the river of COD concentration minimum decrease was at Hexi , $-1.8 \%$. Otherwise, comparison with COD concentrations of input rivers in July , 1998 , and 1997 , the average total decrease was $-14.8 \%$. In 1998 , the decrease was $-39.8 \%$ in September , $-31.9 \%$ in November, and $-20.5 \%$ in December, respectively.

The COD quantity from watershed to Taihu Lake was decreased by 19.1\%. The average COD concentration in Taihu Lake was decreased by $21.2 \%$.

After the" Zero" actions, in the year of 1999 and 2000 , the water qualities in Taihu Lake are deteriorated again. Thus, to control the water quality radically , other countermeasures are needed except" Zero" actions.
\end{abstract}

Key Words “ Zero” action, water environment, effect, Taihu Lake 